\title{
TALENs—an indispensable tool in the era of CRISPR: a mini review
}

\author{
Anuradha Bhardwaj and Vikrant Nain *i]
}

\begin{abstract}
Background: Genome of an organism has always fascinated life scientists. With the discovery of restriction endonucleases, scientists were able to make targeted manipulations (knockouts) in any gene sequence of any organism, by the technique popularly known as genome engineering. Though there is a range of genome editing tools, but this era of genome editing is dominated by the CRISPR/Cas9 tool due to its ease of design and handling. But, when it comes to clinical applications, CRISPR is not usually preferred. In this review, we will elaborate on the structural and functional role of designer nucleases with emphasis on TALENs and CRISPR/Cas9 genome editing system. We will also present the unique features of TALENs and limitations of CRISPRs which makes TALENs a better genome editing tool than CRISPRs.

Main body: Genome editing is a robust technology used to make target specific DNA modifications in the genome of any organism. With the discovery of robust programmable endonucleases-based designer gene manipulating tools such as meganucleases (MN), zinc-finger nucleases (ZFNs), transcription activator-like effector nucleases (TALENs), and clustered regularly interspaced short palindromic repeats associated protein (CRISPR/Cas9), the research in this field has experienced a tremendous acceleration giving rise to a modern era of genome editing with better precision and specificity. Though, CRISPR-Cas9 platform has successfully gained more attention in the scientific world, TALENs and ZFNs are unique in their own ways. Apart from high-specificity, TALENs are proven to target the mitochondrial DNA (mito-TALEN), where gRNA of CRISPR is difficult to import. This review talks about genome editing goals fulfilled by TALENs and drawbacks of CRISPRs.

Conclusions: This review provides significant insights into the pros and cons of the two most popular genome editing tools TALENs and CRISPRs. This mini review suggests that, TALENs provides novel opportunities in the field of therapeutics being highly specific and sensitive toward DNA modifications. In this article, we will briefly explore the special features of TALENs that makes this tool indispensable in the field of synthetic biology. This mini review provides great perspective in providing true guidance to the researchers working in the field of trait improvement via genome editing.
\end{abstract}

Keywords: Genome editing, TALEN, CRISPR, ZFN, Meganuclease

\section{Background}

\section{Genome editing}

Genome editing is a procedure that allows for sitespecific modifications to be made in the genome of any organism [1]. There are two main goals for genome manipulation: one is to learn how new genes function and what functions they play in cell regulation. The second major use of genome manipulation is the creation of alternative treatment options for a variety of genetic

\footnotetext{
*Correspondence: vikrant.nain@gmail.com

Department of Biotechnology, Gautam Buddha University, Greater Noida, Uttar Pradesh 201312, India
}

disorders [2]. The evolution of genome engineering using designer nucleases has brought a paradigm shift in the field of biotechnology. These tools have demonstrated promising results in various domains including medical and agricultural sciences [3]. Also, both TALENs and CRISPR are crucial in elimination of undesired genes [4]. The appealing agricultural applications of nuclease-based genome editing include improved varieties of crops with high yields and desired features like enhanced nutritional content, greater shelf life, better stress tolerance, disease, and pest resistance [5].

\section{Springer Open}

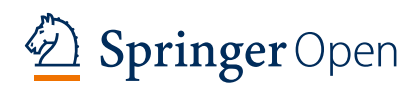

(C) The Author(s). 2021 Open Access This article is licensed under a Creative Commons Attribution 4.0 International License, which permits use, sharing, adaptation, distribution and reproduction in any medium or format, as long as you give appropriate credit to the original author(s) and the source, provide a link to the Creative Commons licence, and indicate if changes were made. The images or other third party material in this article are included in the article's Creative Commons licence, unless indicated otherwise in a credit line to the material. If material is not included in the article's Creative Commons licence and your intended use is not permitted by statutory regulation or exceeds the permitted use, you will need to obtain permission directly from the copyright holder. To view a copy of this licence, visit http://creativecommons.org/licenses/by/4.0/. 
Genome editing is being applied in many plant and animal species. The use of ZFN in marine animals such as zebrafish and many live-stock animals has been shown, while TALEN and CRISPR systems are used in the cell lines of many cattle species such as cows, pigs, and chickens [6,7]. Even genome editing has found its applications in many infectious and non-infectious diseases $[8,9]$. In preliminary experiments, the knocking-in protocol was used to accomplish this aim. Gene editing techniques have been used to treat a host of genetic abnormalities in human cell lines and cancer models [3, 10, 11] These positive results suggest that gene editing strategies have huge potential to treat human genetic diseases like Duchenne muscular dystrophy, cystic fibrosis, sickle cell anemia, and Down syndrome [11]. CRISPR approaches have also demonstrated promise in the detection and treatment of fatal diseases such as AIDS and cancer [12]. However, off-target mutations have been identified as a significant risk of these developments, prompting the adoption of more rigorous standards and the completion of clinical research criteria prior to human germline editing [13].

To modify a target gene, the genome-editing tools are designed to create a double-stranded break (DSB) precisely at the target specific region [14]. DSBs are particularly deleterious, but all living species have evolved repair mechanisms to restore the initial sequence in order to protect the functionality of their genomes. As soon as the DSB is created, either of the DNA repair pathways gets activated: (a) The error-prone nonhomologous end joining (NHEJ) and (b) accurate homologous recombination (HR) (Fig. 1). NHEJ is preferred for gain/loss of function applications due to its mutagenic behavior of possible insertions or deletions (Indels) resulting in altered reading frames. In contrast, HR is cell cycle dependent (S/G2 phase) event having reduced efficiency of editing a genome due to its dependence on a template to accomplish repair. HR is usually preferred for gene knock-out/in experiments [15]. HR is usually preferred as its occurrence is governed by the cell cycle. Both of these mechanisms are extensively employed to manipulate genes.

Out of three genome editing technologies (ZFN, TALEN, and CRISPR) available, TALENs and CRISPR are common in practice to make site-specific gene modifications [16, 17]. Figure 2 shows the mechanism of action of these genome editing tools TALENs and CRISPR/Cas9 system on a DNA double strand resulting

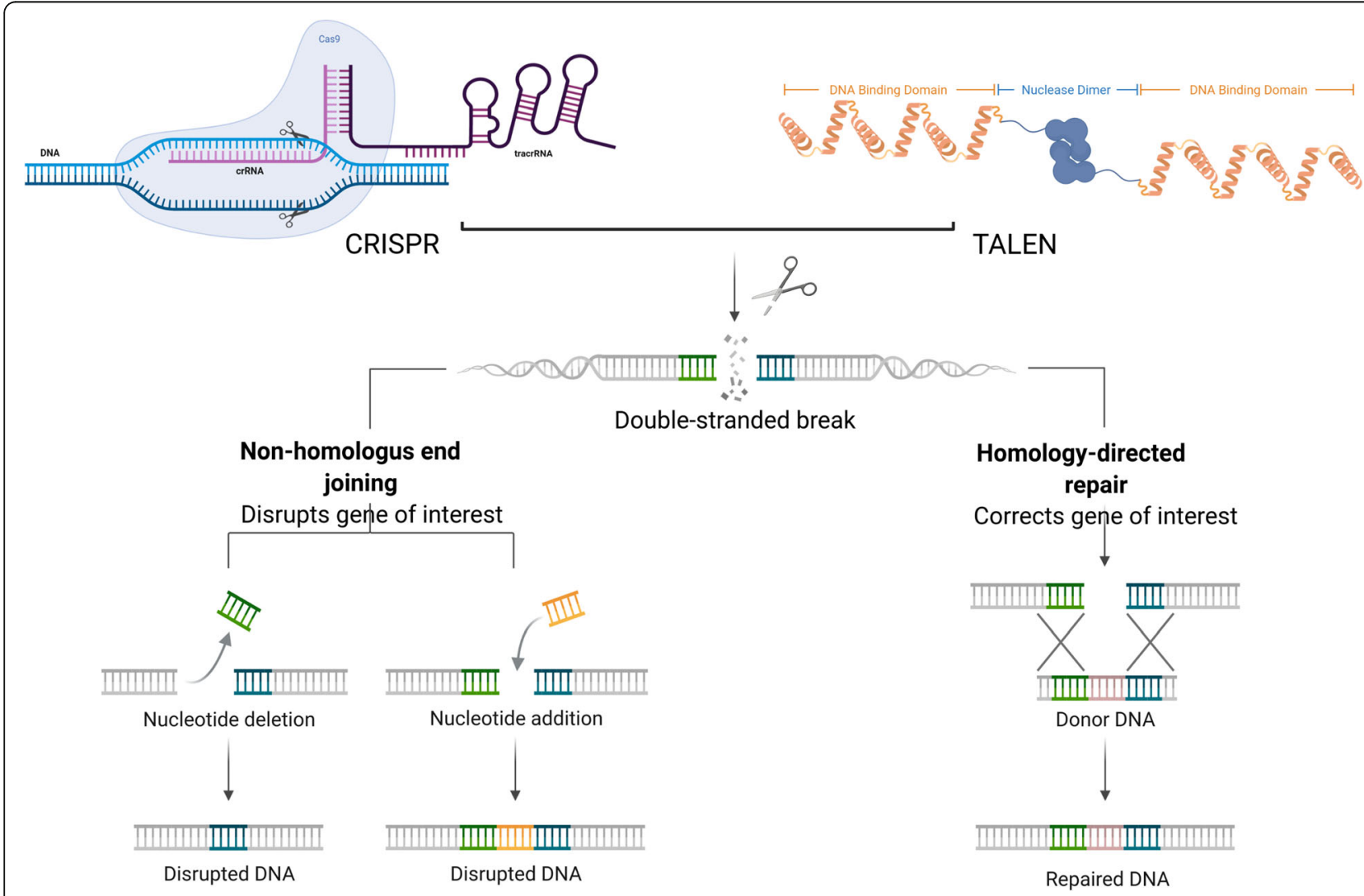

Fig. 1 Schematic illustration of genome editing nucleases inducing double-strand break (DSB) in target DNA. DSBs activate the DNA repair pathways: the error-prone nonhomologous end joining (NHEJ) or accurate but template dependent homologous recombination (HR) 


\section{Mechanism of Action}

CRISPR-Cas9
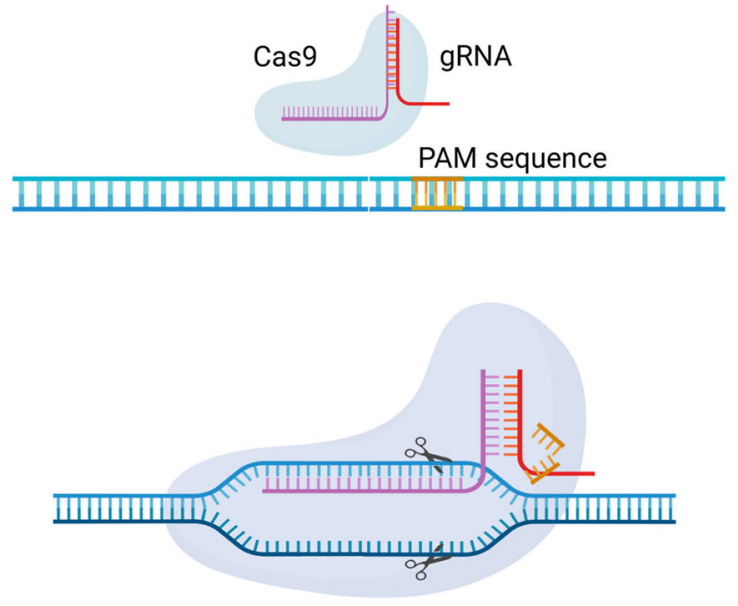

TALEN

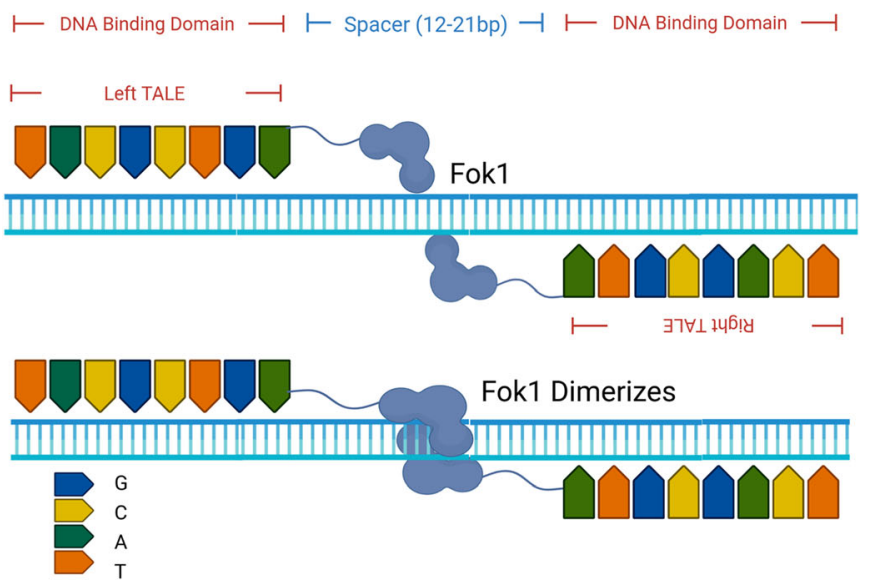

Fig. 2 Schematic illustration of mode of action of genome editing nuclease (TALENs and CRISPRs) inducing a double-strand break on the target DNA

in induction of DSBs and activation of different cell repair pathways. Both the tools manipulate genomes at the desired site, but they are structurally and functionally entirely different. While TALEN recognizes the target site on the basis of DNA protein interaction, CRISPR system is based on site specific RNA protein interactions [4]. This fundamental structural difference in TALEN and CRISPR leads to their strengths and weaknesses in terms of designing, synthesis, efficiency, specificity, and off target activity. In this mini review, we have discussed some of the unique features of TALENs that make it mighty in this epoch of CRISPR (Table 1).

\section{CRISPR}

The CRISPR/Cas9 system for genome editing is considered the biggest scientific development of the decade, leading the Nobel prize to its inventors and opening up tremendous opportunities in the field of medicine and sustainable improvement in agriculture [18].The Cas9 (CRISPR-associated) enzyme, which is part of the type II CRISPR system that makes up S. Pyogenes bacteria's innate immune system, has ushered this generation of genome engineering owing to its flexible use and easy construction. To configure Cas9 to knockout a given target DNA, the order of the guide RNA (gRNA) sequence must be designed to have a $5^{\prime}$ end complementary to

Table 1 Comparison of TALEN and CRISPR/Cas9-mediated genome editing

\begin{tabular}{lll}
\hline Feature & TALEN & CRISPR/Cas9 \\
\hline Recognition type & DNA-Protein & DNA-RNA \\
Target site length & $30-36 \mathrm{bp}$ & $23 \mathrm{bp}$ \\
Endonuclease & Fok1 & Cas9 \\
Dimerization & Required & Not required \\
Off-target & Low & High \\
Design and Assembly & Labour intensive & Easy \\
Target Range & Unlimited & Limited by PAM \\
Degenerate Recognition & Yes & No \\
Specificity & High, few mismatches tolerated & Moderate, comparatively more mismatches tolerated \\
DNA methylation sensitive & Yes & No \\
Mitochondrial Genome Engineering & Easy & Complicated \\
Precision of Genome Editing & High & Moderate \\
\hline
\end{tabular}


the target site [19]. Cas9 targeting is simple to program compared to the more intensive genome editing tools (MNs, ZFNs, and TALENs). The endonuclease of the CRISPR-Cas9 system whose activity to specifically cleave DNA is governed by a short gRNA sequence (20bp). In Cas9 mediated targeting, the 5'-NGG-3' PAM (protospacer-associated motif) interacting domain confers specificity and is therefore responsible for specifying the explicit binding site on target DNA. The Cas enzyme diversity is rich in various species that have different PAM requirements [20]. The CRISPR-Cas9 technology has been successfully operated in a variety of cells, organisms, and even human cells for medicinal purposes [21]. However, it is critical to note the high risk of off-target mutations as a significant shortcomings of the CRISPR/ Cas9 platform [22].

\section{Limitations of CRISPR technology}

Despite their wide range of applications, these designer nucleases are not thought to be safe or precise enough for site-directed therapies, particularly in gene therapy. Though off-target effects exist in all genome editing systems, the high prevalence ( $\geq 50 \%$ ) of unpredictable offtargets in CRISPR/Cas9 technology is a major disadvantage [6]. Researchers have endeavored to mitigate CRISPR off-targets by creating novel Cas9 variants and improving the gRNA architecture [23], but these strategies have not been very efficient. Another disadvantage of this technology is the need for a PAM near the target location. With a short canonical PAM recognition site of 5' NGG3', where $\mathrm{N}$ can be any nucleotide, Cas9 from the bacteria Streptococcus pyogenes (SpCas9) is one of the most commonly used Cas9s. Furthermore, spCas9 is difficult to package into AAV vectors, the most popular gene therapy delivery vehicle, because of its bulky size [24]. CRISPR-induced DSBs often cause apoptosis resulting in DNA damage and cellular toxicity [25]. All traditional gene editing systems have technical flaws and functional drawbacks, raising concerns about their practical use in the real world.

\section{TALEN}

TALEs proteins were first reported in 2009, derived from phytopathogenic bacterial genus Xanthomonas [26]. TALE is a special class of proteins that can bind DNA. TALEs offers flexible applications in genetic engineering due to its compatibility with many functional domains. Different associations of TALE proteins with transcriptional activators, repressors, or endonucleases give them potential transformation from transcriptional modulators to genome editing tools [27]. In the year 2011, the TALEN system was voted as the tool of the year by Nature Methods [28] due to its high specificity and precision in genome engineering making it an efficient tool.

A typical TALEN unit comprises a central DNAbinding domain of 12-28 repeats, a nuclear localization signal (NLS), an acidic domain for target gene transcription activation, and Fok1 nuclease [28]. The DNA-interacting region is a preserved sequential arrangement of significantly constant 33-35 amino acids with polymorphic 12 and 13 repeat variable diresidues (RVDs). Each repeat uniquely binds to a single nucleotide in the $5^{\prime}$ to $3^{\prime}$ orientation on the target [29]. The biochemical structure-function studies suggest that the amino acid present at the place 13 uniquely identifies a nucleotide on the DNA target major groove [30-32]. This DNA-protein interaction unit is stabilized by the amino acid at place 12 . At the 3 '-end of target locus, a half repeat of only 20 amino acids exists to bind the DNA sequence.

The four most common RVDs identified by various experimental validations are NN, NG, HD, and NI with unique preferential binding affinity toward G/A, T, C, and A respectively bestowing target specificity [33]. Remarkably screening of all 400 possible combinations of RVDs is also reported [34], which are considered as non-conventional RVDs because of their rare existence in nature [35].

The popularly used TALEN system comprises 2 units of DNA binding domain (DBDs) from TALE proteins. Each unit is attached with a catalytic domain from Folk1 restriction enzyme. Fok1 nuclease of the TALENs dimerizes which generates a cleavage on both the strands of DNA-double helix, activating the DNA repair machinery to fix disruption.

As we align repeat modules (RVDs) in a particular structure, it is possible to create TALENS with the required sequence precision. There is, however, a limit to the option of target sites for TALEN. A thymine at position 0 , i.e., immediately precursory to the TALE-repeat bound sequences is invariably required [32]. The complete gene activation is ensured by the weak van der Waal forces acting between the C5 methyl group of thymine and the extremely conserved tryptophan in the $\mathrm{N}$-terminal. Newer versions of TALEs are also reported in nature that replaces thymine with cytosine at position 0 with no effect on their activity. These scaffolds are independent of the prerequisite 5'T [36]. Nonetheless, customizing TALE-based tools to alter any genome is quite versatile but simple. The crystal structure of TALE proteins bound to target DNA reveals that each repeating unit forms a v-shaped structure consisting of two alpha helix assembled to form a solenoid-like structure wrapped around the major groove of DNA via the hypervariable 12 and 13 amino acids [31, 32]. 


\section{Characteristic features of TALENs Specificity}

This era of gene targeting is ruled by the two very recent and robust engineering nucleases, TALEN and CRISPR. CRISPR-Cas9 is a very familiar tool for many molecular biologist greatly known for its easy-programming of gRNA feature [37]. Since nucleases can cause unintended interruptions in the genome, gene editing is crucial and as multiplex methods become more widely used, the likelihood of off-targets and the downstream consequences of such off-target activity grow. Minimizing these undesired cleavage (off-targets) is a matter of utmost importance for any genome-engineering applications, especially in the therapeutic domain. Unwanted double-stranded breaks in the genome may lead to chromosome translocation, and cellular toxicity [38]. There are currently a wide variety of techniques available to predict and resolve off-target behaviors by analyzing secondary target locations [39-43].

The gRNA of CRISPR is an integrated product of custom-designed crRNA and trRNA scaffold [19]. On the target DNA, the sgRNA specifically guides the Cas9 of $S$. pyogenes to recognize its unique Protospacer Adjacent Motif, or PAM immediately adjacent to a 20nucleotide target site where gRNA hybridizes (Watsoncrick base pairing) with the strand opposite the PAM site channelizing Cas9 to cut DNA. CRISPR has been shown in a number of recent papers to induce DSB formation at very high frequencies at the desired DNA locus [44].

On the other hand, TALEs have a well-defined DNA base-pair choice, offering a basic strategy for scientific researchers and engineers to design and construct TALEs for genome alteration. Engineered TALES can currently be used in cells and model organisms. A protein repeat tandem is responsible for recognizing individual DNA base pairs. Tandem repeats are made up of a pair of alpha helices linked by a loop of three-residue of RVDs in the shape of a solenoid. For the creation of TALEs with variable precision and binding affinity, the six conventional RVDs (NG, HD, NI, NK, NH, and NN) are frequently used. HD and NG are associated with cytosine $(\mathrm{C})$ and thymine $(\mathrm{T})$ respectively. These associations are strong and exclusive [45].

$\mathrm{NN}$ is a degenerate RVD showing binding affinity for both guanine $(G)$ and adenine $(A)$, but its specificity for guanine is reported stronger. RVD NI binds with $\mathrm{A}$ and NK binds with G. These associations are exclusive but the binding affinity between these pairs is less due to which they are considered weak. Therefore, it is recommended to use RVD NH which binds with $\mathrm{G}$ with medium affinity. It is also worth noting that the binding affinity of TALE is influenced by the methylation status of the target DNA sequence [45].
A typical TALEN system usually consists of 18 repeats of 34 amino acids. A TALEN pair must bind to the target site on opposite sides, separated by a "spacer" of 1420 nucleotides as an offset since FokI requires dimerization for operation. As a whole, such a long (approximately $36 \mathrm{bp}$ ) DNA binding site is predicted to appear in genomes very rare.

Remarkably, the high degree of specificity and low cytotoxicity of TALENs has been applied in diverse cell types [46]. Despite having more efficiency than TALEN, CRISPR-Cas9 system is prone to off-targets effects [4751]. Most importantly, off-targets are a rare event in TALEN-mediated systems which make it a better choice for the purpose of genome editing [52]. This high level of specificity becomes important when we have to target a particular gene belonging to a gene family or a specific allele in a polyploid plant species.

\section{Degeneracy}

The TALEN code is degenerate, which means that certain RVDs can bind to multiple nucleotides with a diverse spectrum of efficiency. The binding ability of the NN (for A and G) and NS (A, C, and G) repeat variable di-residue empowers the TALENs to encode degeneracy for the target DNA [26]. This degeneracy may be useful in targeting hyper variable sites. TALENs technology is the only known genome editing tool which can be engineered in a way that can be easily used for the escape mutations in a genome [26]. This unique feature of TALENs make them a more flexible and reliable tool in the field of genome editing specifically in clinical applications to tolerate predicted mutations [53].

\section{Methyl sensitivity}

Apart from the four typical nucleotides A, T, G and C, the epigenetic DNA nucleobases 5-methylcytosine $(5 \mathrm{mc})$ and 5-hydroxymethylcytosine $(5 \mathrm{mhc})$ plays important regulatory roles, contributing to around $75 \%$ of $\mathrm{CpG}$ islands in a mammalian genome $[46,54]$. They are key molecules in diverse biological processes ranging from development-related events like gene expression and gene silencing to a diseased state like X chromosome inactivation. CRISPR-Cas9 is binding place base-pairing between gRNA and the target DNA, which makes it insensitive to distinguish the methylation modifications of cytosine. A recently demonstrated method using the catalytically dead Cas9 (dCas9) fused to the DNA methyltransferase domain for detection of the methylation of CpG dinucleotides has been reported [55-57]. This method has lower efficiency and results in multiple CpGs methylation in the vicinity of the target site. In the case of a CpG island, low sequence complexity and targeting ambiguities can complicate guide design. A drawback of this method is that it fails to distinguish between 
the effects of the binding of the fusion protein vs. methylation itself for investigations of the functional consequences of methylation.

On the other hand, TALE proteins can be successfully re-engineered with sensitivity toward these DNA chemical modifications. Methylated cytosine is not efficiently bound by the canonical RVD HD; however, owing to the high structural resemblance of methylated cytosine to thymine, NG is capable of binding to methylated cytosine [58]. Also, for a given target DNA, engineered TALEs with a combination of HD for $\mathrm{C}, \mathrm{N}^{*}$ for $5 \mathrm{mC}, \mathrm{Q}^{*}$ for $5 \mathrm{mhC}$, are used as DNA binding receptors to directly distinguish methylated cytosines $(5 \mathrm{mC}, 5 \mathrm{mhC})$ from unmethylated cytosine (C) [59-61] Even in the case of methylated cytosines, the peculiar characteristic of degeneracy in TALENs exists. RVD R*, for example, codes for both $5 \mathrm{mC}$ and $5 \mathrm{mhC}$ epigenetic nucleobases, while RVD $\mathrm{Q}^{*}$ is a universal RVD that associates with both $C, 5 \mathrm{mC}$, and $5 \mathrm{mhC}$ epigenetic nucleobases making it a powerful and versatile tool for genome editing [62].

\section{Cell organelle DNA targeting}

CRISPR-Cas9 is known for its broad spectrum of successful applications in this modern era of nuclear DNA editing, but researchers find it challenging to import the gRNA and Cas9 complex to reach into the mitochondria to selectively eliminate mutations. The CRISPR/Cas9 platform, tailored to mitochondria, could prompt a revolution in mitochondrial genome engineering and biological understanding [63]. However, the presence of an endogenous system, a prerequisite for mitochondrial CRISPR/Cas9 gene editing, for nucleic acid induction into mammalian mitochondria, remains unclear [64]. TALEN, on the other hand, has the ability to efficiently manipulate mtDNA (mitochondrial DNA) as a treatment for treating human mitochondrial diseases triggered by mitochondrial pathogenic mutations [54]. Mito-TALENs (mitochondrial-targeted TALENs) have also been proven to be effectively treating human mitochondrial disorders affected by mtDNA mutations, such as Leber's hereditary optic neuropathy, ataxia, neurogenic muscle fatigue, and retinal pigmentosa [55]. Plastid engineering has also demonstrated competent results in limited varieties of plants for crop improvements [65].

\section{Development of artificial transcription factors}

Control over the endogenous gene expression has always fascinated scientists. Programmable designer transcription factors fused to desired transcriptional activator and repressor protein domains provides this flexibility to the researchers to keep a strong hold on transcriptional machinery of a gene. Before their application in genome modifications, proteins like ZFN and TALE have demonstrated a wide range of applications in this sector of modulating the expression of any gene of any organism [66, 67].

Most recently, a novel modified version of the easy to design non-functional Cas9 based CRISPR-Cas9 system was also developed to be used as an artificial transcription factor; however, due to the large size of the complex, it is not as efficient as TALE protein-based artificial transcription factors.

\section{Development of transcription activators}

Artificial transcription factors were first generated by the fusion of engineered zinc finger protein with a 16 amino acid peptide (VP16) from herpes simplex virus as a transactivation domain [68]. With a glycine-serine linkage between four consecutive VP16, a novel assembly of synthetic transcription factor VP64 was then assembled [69]. However, this tool suffered a problem of high incidence of off-targets. As a modified version of zinc-finger transcription factors, TALE transcription factors have emerged as a crucial tool for achieving selective transcriptional regulation [70]. In contrast with zinc-fingers, TALEs are efficient transcription modulators with only 10.5 repeats with an effector module fused to the carboxyl terminal [71]. TALEs in the form of activators have been used to control the gene expression in case of external stimuli like a chemical change, or optical stimulus [72]. TALE transcription factors are used in various organisms including plants and animals.

To explore CRISPR/Cas9 as a transcription modulator, the Cas9 protein of the system is catalytically deactivated and then fused with the desired effector domains like VP64 [73]. The inactivation of Cas9 protein to form dead/deactivated Cas9 (dCas9) is accomplished by D10A and H840A amino acid substitutions in the RuvC and NHN endonuclease domains, respectively. Though catalytically inactive, dCas9 retains its specificity to bind at the gRNA directed site on the target $[55,74]$.

\section{Development of transcription repressors}

Earlier in its old versions, CRISPR/Cas9 acts as a repressor modulator of transcription by blocking the target site. The steric hindrance of the CRISPR system hindered the transcription machinery to affect the target on the DNA. In the modified version, the involvement of the repression domain was more efficient than only steric repulsions. In the revised versions, a mechanism known as CRISPR interference in which the dead Cas9 protein blocks the gene expression by obstructing the transcription start site is also in practice. Fusing dCas9 to transcriptional repressor domains is another way to effectively silence a gene from the promoter [75]. To accomplish repression of a gene, the robust TALE proteins 
are attached with either Kruppel-associated box (KRAB), Sid4, or EAR-repression domain (SRDX) repressors [76].

\section{Editing the epigenome}

Natural modifications in the cytosine base are absolutely necessary to maintain regulation of genome expression and genome stability. ATFs are programmed to engineer the epigenome to modulate the expression of a gene without altering the DNA sequence. These epigenome editing techniques help us explore the role of epigenetics in the crucial process of gene expression. Moreover, epigenome editing uncovers the exact sequence of events of chromatin remodeling and its effect of gene expression, which is key to understanding many biological processes and diseases in humans. In comparison with ZFNs, TALE-proteins have significantly emerged as critical DNA-binding scaffolds governed by a simple cipher. Their compatibility with a broad range of epigenetic modifiers is commendable [77]. With these DNAbinding proteins, it is possible to target an epigenetic effector domain to any locus in the genome [78].

\section{Modifying histones}

To understand the function of histone modifications, zinc-finger proteins were fused with a methyltransferase in a research by Carl who successfully demonstrated that the methylation of $\mathrm{H} 3 \mathrm{~K} 9$ can ultimately result in gene repression [79]. The lysine-specific histone demethylase 1 (LSD1) domain is sensitive in detecting histone demethylation. A hybrid TALE with LSD1 has been successfully employed to bring out histone modifications to reveal its function [80]. The lab of Feng Zhang has created an optogenetic epiTALE system in which an inducible element both activates and represses transcription via effector domains, many of which modify histones [81]. CRISPR/ dCas9 fused with a p300 effector domain creates to activate enhancers by histone acetyltransferase.

\section{DNA—cytosine demethylases}

A wide range of cytosine modifications naturally exists like 5 methylcytosine $(5 \mathrm{mC})$ and 5 hydroxymethyl $(5 \mathrm{hmC})$. Unwanted DNA methylations are associated with many neurodegenerative diseases. The catalytic domain thymidine DNA glycosylase (TDG) was first demonstrated to abolish the DNA methylation and induce gene expression [82]. In the clinical practices, the hybrid zinc finger protein with TET domain (ten-eleven translocation methylcytosine dioxygenase 2) has demonstrated a great potential for targeting epigenetically silenced cancer gene (ICAM-1) and induce its expression in cancerous cells $[73,82]$. The CRISPR-dCas9 fusion with TET1 has been successfully used in the treatment of many diseases like diabetes (inducing $\beta$ cell replication) and cancer (inhibiting cell proliferation) $[83,84]$.

\section{Delivery of TALENS vs CRISPR}

For the real-world clinical applications of the genome editing systems, it is important to develop efficient in vivo delivery strategies to improve safety. The traditional in vivo delivery methods are either viral vector based or non-viral vector based. Viral vectors such as adeno-associated virus (AAV), adenovirus (AdV), and lentivirus (LV), are well established to carry and deliver small ZFNs and even TALENs into target cells, but are not generally preferred for the CRISPR-Cas9 system due to its bulky architecture and large cargo size $(\sim 4.3 \mathrm{~kb})$ (effect of genome size on AAV vector packaging). Viral vectors are popular for the delivery of nucleases in the cells with well-established protocols as they do not cause insertional mutagenesis and have higher efficiency. Though, it is reported that the LV-encapsulated delivery vector of CRISPR-Cas9 system for gene therapy produced efficient-targeted mutations but higher risk of offtargets limits its applications. In contrast, the easily designed and constructed non-viral vectors have capability to carry large size designer nucleases but their low transfection efficiency and poor specificity causes high cellular toxicity which limits their use in gene therapy [85].

\section{Conclusions}

TALEN is a robust and promising genome editing tool which offers the scientific community a wide choice to target unlimited sequences of any organism. It is a powerful tool with high specificity and precision with low cytotoxicity which makes it ideal for therapeutic applications especially in humans. It is easy and relatively cheap to design and assemble TALENs and thus it becomes the first choice for targeted mutagenic applications. The potentials of TALENs are neglected over CRISPR due to its ease of design but, when it comes to the real world problems, the outstanding competence of TALENs is undoubted.

\section{Abbreviations}

MN: Meganucleases; ZFNs: Zinc-finger nucleases; TALENs: Transcription activator-like effector nucleases; CRISPR/Cas9: Clustered regularly interspaced short palindromic repeats associated protein; DSB: Double-stranded break; NHEJ: Nonhomologous end joining; HR: Homologous recombination; gRNA: Guide RNA

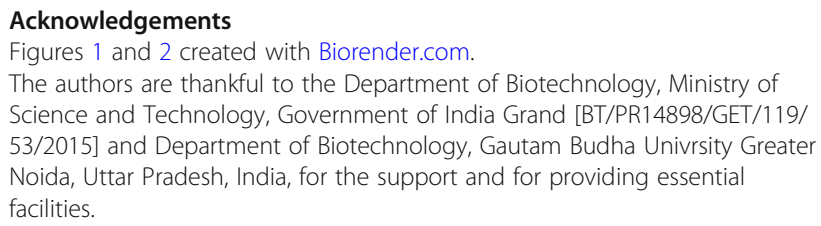

Authors' contributions

$A B$ performed overall writing of the paper including research, literature review, and analysis of data. VN conceived the idea, performed overall supervision of research work and editing of the review paper. All authors read and approved the final manuscript. 


\section{Funding}

This research was funded by Department of Biotechnology, Ministry of Science and Technology, Government of India Grand [BT/PR14898/GET/119/ $53 / 2015]$. The funder does not have any role in the design of the study or making any conclusions.

\section{Availability of data and materials}

Not applicable

\section{Declarations}

\section{Ethics approval and consent to participate}

Not applicable

\section{Consent for publication}

Not applicable

\section{Competing interests}

The authors declare that they have no competing interests.

Received: 5 June 2021 Accepted: 8 August 2021

Published online: 21 August 2021

\section{References}

1. Chen K, Gao C (2014) Targeted genome modification technologies and their applications in crop improvements. Plant Cell Rep 33(4):575-583. https://doi.org/10.1007/s00299-013-1539-6

2. Tschaharganeh DF, Lowe SW, Garippa RJ, Livshits G (2016) Using CRISPR/Cas to study gene function and model disease in vivo. FEBS J 283(17):31943203. https://doi.org/10.1111/febs.13750

3. Li H, Yang Y, Hong W, Huang M, Wu M, Zhao X (2020) Applications of genome editing technology in the targeted therapy of human diseases: mechanisms, advances and prospects. Signal Transduct Target Ther 5(1):1. https://doi.org/10.1038/s41392-019-0089-y

4. Nemudryi AA, Valetdinova KR, Medvedev SP, Zakian SM (2014) TALEN and CRISPR/Cas genome editing systems: tools of discovery. Acta Nat 6(3):19-40. https://doi.org/10.32607/20758251-2014-6-3-19-40

5. Gao C (2021) Genome engineering for crop improvement and future agriculture. Cell 184(6):1621-1635. https://doi.org/10.1016/j.cell.2021.01.005

6. Fernandez JP, Vejnar CE, Giraldez AJ, Rouet R, Moreno-Mateos MA (2018) Optimized CRISPR-Cpf1 system for genome editing in zebrafish. Methods 150:11-18. https://doi.org/10.1016/j.ymeth.2018.06.014

7. Mooney MR, Davis EE, Katsanis N (2019) Analysis of single nucleotide variants in CRISPR-Cas9 edited zebrafish exomes shows no evidence of offtarget inflation. Front Genet 10. https://doi.org/10.3389/fgene.2019.00949

8. Puria R, Sahi S, Nain V (2012) HER21 breast cancer therapy: by CPP-ZFN mediated targeting of mTOR? Technol Cancer Res Treat 11(2):175-180. https://doi.org/10.7785/tcrt.2012.500247

9. Nain V, Sahi S, Verma A (2010) CPP-ZFN: a potential DNA-targeting antimalarial drug. Malar J 9(1):258. https://doi.org/10.1186/1475-2875-9-258

10. Doudna JA, Charpentier $E$ (2014) The new frontier of genome engineering with CRISPR-Cas9. Science 346:1258096

11. Wu WH, Tsai YT, Justus $S$ et al (2018) CRISPR repair reveals causative mutation in a preclinical model of retinitis pigmentosa: a brief methodology. In: Methods Mol. Biol. Humana Press Inc., pp 191-205

12. Cyranoski D (2016) CRISPR gene-editing tested in a person for the first time. Nature 539(7630):479. https://doi.org/10.1038/nature.2016.20988

13. Greely HT (2019) CRISPR'd babies: Human germline genome editing in the "He Jiankui affair.". J Law Biosci 6:111-183

14. Guha TK, Wai A, Hausner G (2017) Programmable genome editing tools and their regulation for efficient genome engineering. Comput Struct Biotechnol J 15:146-160. https://doi.org/10.1016/j.csbj.2016.12.006

15. Pardo B, Gómez-González B, Aguilera A (2009) DNA double-strand break repair: how to fix a broken relationship. Cell Mol Life Sci 66(6):1039-1056. https://doi.org/10.1007/s00018-009-8740-3

16. Cong L, Ran FA, Cox D et al (2013) Multiplex genome engineering using CRISPR/Cas systems. Science 339:819-823

17. Kaboli S, Babazada H (2018) Crispr-mediated genome engineering and its application in industry. Curr Issues Mol Biol 26:81-92. https://doi.org/10.21 775/cimb.026.081
18. Jiang F, Doudna JA (2017) CRISPR-Cas9 structures and mechanisms. Annu Rev Biophys 46(1):505-529. https://doi.org/10.1146/annurev-biophys-062215 010822

19. Jinek M, Chylinski K, Fonfara I, Hauer M, Doudna JA, Charpentier E (2012) A programmable dual-RNA-guided DNA endonuclease in adaptive bacterial immunity. Science 337:816-821

20. Mojica FJM, Díez-Villaseñor C, García-Martínez J, Almendros C (2009) Short motif sequences determine the targets of the prokaryotic CRISPR defence system. Microbiology 155(3):733-740. https://doi.org/10.1099/mic.0.023960-0

21. Uddin F, Rudin CM, Sen T (2020) CRISPR gene therapy: applications, limitations, and implications for the future. Front Oncol 10:1387. https://doi. org/10.3389/fonc.2020.01387

22. Zhang XH, Tee LY, Wang XG, Huang QS, Yang SH (2015) Off-target effects in CRISPR/Cas9-mediated genome engineering. Mol Ther Nucleic Acids 4:e264. https://doi.org/10.1038/mtna.2015.37

23. Jonlin EC (2020) Informed consent for human embryo genome editing. Stem Cell Rep 14(4):530-537. https://doi.org/10.1016/j.stemcr.2020.03.010

24. Park JY, Moon BY, Park JW, Thornton JA, Park YH, Seo KS (2017) Genetic engineering of a temperate phage-based delivery system for CRISPR/Cas9 antimicrobials against Staphylococcus aureus. Sci Rep 7(1):44929. https://doi. org/10.1038/srep44929

25. Robb GB (2019) Genome editing with CRISPR-Cas: an overview. Curr Protoc Essent Lab Tech 19(1). https://doi.org/10.1002/cpet.36

26. Boch J, Scholze H, Schornack S, Landgraf A, Hahn S, Kay S, Lahaye T, Nickstadt A, Bonas U (2009) Breaking the code of DNA binding specificity of TAL-type III effectors. Science 326:1509-1512

27. Thakore PI, Gersbach CA (2016) Design, assembly, and characterization of tale-based transcriptional activators and repressors. In: Methods Mol. Biol. Humana Press Inc., pp 71-88

28. (2012) Method of the year 2011. Nat Methods 9:1

29. Boch J, Scholze H, Schornack S, Landgraf A, Hahn S, Kay S, Lahaye T, Nickstadt A, Bonas U (2011) Effectors breaking the code of DNA binding specificity of TAL-Type III. Science 326(5959):1509-1512. https://doi.org/1 $0.1126 /$ science. 1178811

30. Stella S, Molina R, Yefimenko I, Prieto J, Silva G, Bertonati C, Juillerat A, Duchateau P, Montoya G (2013) Structure of the AvrBs3-DNA complex provides new insights into the initial thymine-recognition mechanism. Acta Crystallogr Sect D Biol Crystallogr 69(9):1707-1716. https://doi.org/10.1107/ S0907444913016429

31. Deng D, Yan C, Pan X, Mahfouz M, Wang J, Zhu JK, Shi Y, Yan N (2012) Structural basis for sequence-specific recognition of DNA by TAL effectors. Science 335:720-723

32. Mak ANS, Bradley P, Cernadas RA, Bogdanove AJ, Stoddard BL (2012) The crystal structure of TAL effector PthXo1 bound to its DNA target. Science 335:716-719

33. Mussolino C, Cathomen T (2012) TALE nucleases: tailored genome engineering made easy. Curr Opin Biotechnol 23(5):644-650. https://doi. org/10.1016/j.copbio.2012.01.013

34. Miller JC, Zhang L, Xia DF, Campo JJ, Ankoudinova IV, Guschin DY, Babiarz JE, Meng X, Hinkley SJ, Lam SC, Paschon DE, Vincent Al, Dulay GP, Barlow KA, Shivak DA, Leung E, Kim JD, Amora R, Urnov FD, Gregory PD, Rebar EJ (2015) Improved specificity of TALE-based genome editing using an expanded RVD repertoire. Nat Methods 12(5):465-471. https://doi.org/10.103 8/nmeth.3330

35. Juillerat A, Pessereau C, Dubois G, Guyot V, Maréchal A, Valton J, Daboussi F Poirot L, Duclert A, Duchateau P (2015) Optimized tuning of TALEN specificity using non-conventional RVDs. Sci Rep 5(1). https://doi.org/10.103 8/srep08150

36. Lamb BM, Mercer AC, Barbas CF (2013) Directed evolution of the TALE Nterminal domain for recognition of all 50 bases. Nucleic Acids Res 41(21): 9779-9785. https://doi.org/10.1093/nar/gkt754

37. Graham DB, Root DE (2015) Resources for the design of CRISPR gene editing experiments. Genome Biol 16(1):260. https://doi.org/10.1186/s13059015-0823-x

38. Cantoni O, Sestili P, Guidarelli A, Palomba L, Brambilla L, Cattabeni F (1996) Cytotoxic impact of DNA single vs double strand breaks in oxidatively injured cells. Arch Toxicol Suppl 18:223-235. https://doi.org/10.1007/978-3642-61105-6_23

39. Tsai S, Nguyen N, Malagon-Lopez J, Topkar W, Aryee MJ, Joung JK (2017) CIRCLE-seq: a highly sensitive in vitro screen for genome-wide CRISPR-Cas9 nuclease off-targets. Nat Methods 14(6):607-614 
40. Hockemeyer D, Wang H, Kiani S, Lai C, Gao Q, Cassady JP, Cost GJ, Zhang L, Santiago Y, Miller JC, Zeitler B, Cherone JM, Meng X, Hinkley SJ, Rebar EJ, Gregory PD, Urnov FD, Jaenisch R (2011) Genetic engineering of human pluripotent cells using TALE nucleases. Nat Biotechnol 29(8):731-734

41. Hockemeyer D, Soldner F, Beard C, Gao Q, Mitalipova M, DeKelver RC, Katibah GE, Amora R, Boydston EA, Zeitler B, Meng X, Miller JC, Zhang L, Rebar EJ, Gregory PD, Urnov FD, Jaenisch R (2009) Efficient targeting of expressed and silent genes in human ESCs and iPSCs using zinc-finger nucleases. Nat Biotechnol 27(9):851-857

42. Wienert B, Wyman S, Richardson C, Yeh CD, Akcakaya P, Porritt MJ, Morlock M, Vu JT, Kazane KR, Watry HL, Judge LM, Conklin BR, Maresca M, Corn JE (2019) Unbiased detection of CRISPR off-targets in vivo using DISCOVERSeq. Science 364(6437):286-289

43. Cheng Y, Tsai SQ (2018) Illuminating the genome-wide activity of genome editors for safe and effective therapeutics. Genome Biol 19(1):226. https:// doi.org/10.1186/s13059-018-1610-2

44. Wang T, Wei JJ, Sabatini DM, Lander ES (2014) Genetic screens in human cells using the CRISPR-Cas9 system. Science 343:80-84

45. Streubel J, Blücher C, Landgraf A, Boch J (2012) TAL effector RVD specificities and efficiencies. Nat Biotechnol 30(7):593-595. https://doi.org/1 0.1038/nbt.2304

46. Mussolino C, Alzubi J, Fine EJ, Morbitzer R, Cradick TJ, Lahaye T, Bao G, Cathomen T (2014) TALENs facilitate targeted genome editing in human cells with high specificity and low cytotoxicity. Nucleic Acids Res 42(10): 6762-6773. https://doi.org/10.1093/nar/gku305

47. Mali P, Aach J, Stranges PB, Esvelt KM, Moosburner M, Kosuri S, Yang L, Church GM (2013) CAS9 transcriptional activators for target specificity screening and paired nickases for cooperative genome engineering. Nat Biotechnol 31(9):833-838. https://doi.org/10.1038/nbt.2675

48. Hsu PD, Scott DA, Weinstein JA, Ran FA, Konermann S, Agarwala V, Li Y, Fine EJ, Wu X, Shalem O, Cradick TJ, Marraffini LA, Bao G, Zhang F (2013) DNA targeting specificity of RNA-guided Cas9 nucleases. Nat Biotechnol 31(9):827-832. https://doi.org/10.1038/nbt.2647

49. Cradick TJ, Fine EJ, Antico CJ, Bao G (2013) CRISPR/Cas9 systems targeting $\beta$-globin and CCR5 genes have substantial off-target activity. Nucleic Acids Res 41(20):9584-9592. https://doi.org/10.1093/nar/gkt714

50. Pattanayak V, Lin S, Guilinger JP, Ma E, Doudna JA, Liu DR (2013) Highthroughput profiling of off-target DNA cleavage reveals RNA-programmed Cas9 nuclease specificity. Nat Biotechnol 31(9):839-843. https://doi.org/10.1 038/nbt.2673

51. Fu Y, Foden JA, Khayter C, Maeder ML, Reyon D, Joung JK, Sander JD (2013) High-frequency off-target mutagenesis induced by CRISPR-Cas nucleases in human cells. Nat Biotechnol 31(9):822-826. https://doi.org/10.1038/nbt.2623

52. Joung JK, Sander JD (2013) TALENs: a widely applicable technology for targeted genome editing. Nat Rev Mol Cell Biol 14(1):49-55. https://doi. org/10.1038/nrm3486

53. Strong CL, Guerra HP, Mathew KR, Roy N, Simpson LR, Schiller MR (2015) Damaging the integrated HIV proviral DNA with TALENs. PLoS One 10(5): e0125652. https://doi.org/10.1371/journal.pone.0125652

54. Ooi SKT, O'Donnell AH, Bestor TH (2009) Mammalian cytosine methylation at a glance. J Cell Sci 122(16):2787-2791. https://doi.org/10.1242/jcs.015123

55. Liu X, Wu H, Ji X, Stelzer Y, Wu X, Cell SC (2016) Editing DNA methylation in the mammalian genome. Elsevier

56. Vojta A, Dobrinić $P$, Tadić $V$, Bočkor L, Korać $P$, Julg B, Klasić $M$, Zoldoš V (2016) Repurposing the CRISPR-Cas9 system for targeted DNA methylation. Nucleic Acids Res 44(12):5615-5628

57. Lei $Y$, Zhang $X$, Su J, Jeong M, Gundry MC, Huang Y-H, Zhou Y, Li W, Goodell MA (2017) Targeted DNA methylation in vivo using an engineered dCas9-MQ1 fusion protein. Nat Commun 8:16026

58. Deng D, Yin P, Yan C, Pan X, Gong X, Qi S, Xie T, Mahfouz M, Zhu JK, Yan N, Shi $Y$ (2012) Recognition of methylated DNA by TAL effectors. Cell Res 22(10):1502-1504. https://doi.org/10.1038/cr.2012.127

59. Hu J, Lei Y, Wong WK, Liu S, Lee KC, He X, You W, Zhou R, Guo JT, Chen X, Peng $X$, Sun $H$, Huang $H$, Zhao $H$, Feng B (2014) Direct activation of human and mouse Oct4 genes using engineered TALE and Cas 9 transcription factors. Nucleic Acids Res 42(7):4375-4390. https://doi.org/10.1093/nar/gku109

60. Dupuy A, Valton J, Leduc S, Armier J, Galetto R, Gouble A, Lebuhotel C, Stary A, Pâques F, Duchateau P, Sarasin A, Daboussi F (2013) Targeted gene therapy of xeroderma pigmentosum cells using meganuclease and TALEN ${ }^{T M}$. PLoS One 8(11):e78678. https://doi.org/10.1371/journal.pone. 0078678
61. Valton J, Dupuy A, Daboussi F, Thomas S, Maréchal A, Macmaster R, Melliand K, Juillerat A, Duchateau P (2012) Overcoming transcription activator-like effector (TALE) DNA binding domain sensitivity to cytosine methylation. J Biol Chem 287(46):38427-38432. https://doi.org/10.1074/jbc. C112.408864

62. Liu L, Zhang Y, Liu M, Wei W, Yi C, Peng J (2020) Structural insights into the specific recognition of 5-methylcytosine and 5-hydroxymethylcytosine by TAL effectors. J Mol Biol 432(4):1035-1047. https://doi.org/10.1016/j.jmb.201 9.11 .023

63. Hashimoto M, Bacman SR, Peralta S, Falk MJ, Chomyn A, Chan DC, Williams SL, Moraes CT (2015) MitoTALEN: a general approach to reduce mutant mtDNA loads and restore oxidative phosphorylation function in mitochondrial diseases. Mol Ther 23(10):1592-1599. https://doi.org/10.1038/ mt.2015.126

64. Gammage PA, Moraes CT, Minczuk M (2018) Mitochondrial genome engineering: the revolution may not be CRISPR-Ized. Trends Genet 34(2): 101-110. https://doi.org/10.1016/j.tig.2017.11.001

65. Piatek AA, Lenaghan SC, Neal Stewart C (2018) Advanced editing of the nuclear and plastid genomes in plants. Plant Sci 273:42-49. https://doi.org/1 0.1016/j.plantsci.2018.02.025

66. Santos-Moreno J, Schaerli Y (2020) CRISPR-based gene expression control for synthetic gene circuits. Biochem Soc Trans 48(5):1979-1993. https://doi. org/10.1042/BST20200020

67. Nakazato I, Okuno M, Yamamoto H, Tamura Y, Itoh T, Shikanai T, Takanashi H, Tsutsumi N, Arimura SI (2021) Targeted base editing in the plastid genome of Arabidopsis thaliana. Nat Plants 7(7):906-913. https://doi.org/1 0.1038/s41477-021-00954-6

68. Yaghmai R, Cutting GR (2002) Optimized regulation of gene expression using artificial transcription factors. Mol Ther 5(6):685-694. https://doi.org/1 $0.1006 /$ mthe. 2002.0610

69. Sadowski I, Ma J, Triezenberg S, Ptashne M (1988) GAL4-VP16 is an unusually potent transcriptional activator. Nature 335(6190):563-564. https:// doi.org/10.1038/335563a0

70. Zhang Y, Zhang F, Li X, Baller JA, Qi Y, Starker CG, Bogdanove AJ, Voytas DF (2013) Transcription activator-like effector nucleases enable efficient plant genome engineering. Plant Physiol 161(1):20-27. https://doi.org/10.1104/ pp.112.205179

71. Miller JC, Tan S, Qiao G, Barlow KA, Wang J, Xia DF, Meng X, Paschon DE, Leung E, Hinkley SJ, Dulay GP, Hua KL, Ankoudinova I, Cost GJ, Urnov FD, Zhang HS, Holmes MC, Zhang L, Gregory PD, Rebar EJ (2011) A TALE nuclease architecture for efficient genome editing. Nat Biotechnol 29(2): 143-148. https://doi.org/10.1038/nbt.1755

72. Konermann S, Brigham MD, Trevino AE, Joung J, Abudayyeh OO, Barcena C, Hsu PD, Habib N, Gootenberg JS, Nishimasu H, Nureki O, Zhang F (2015) Genome-scale transcriptional activation by an engineered CRISPR-Cas9 complex. Nature 517(7536):583-588. https://doi.org/10.1038/nature14136

73. Qi LS, Larson MH, Gilbert LA, Doudna JA, Weissman JS, Arkin AP, Lim WA (2013) Repurposing CRISPR as an RNA-yuided platform for sequence-specific control of gene expression. Cell 152(5):1173-1183. https://doi.org/10.1016/j. cell.2013.02.022

74. Zheng Y, Shen W, Zhang J, Yang B, Liu YN, Qi H, Yu X, Lu SY, Chen Y, Xu YZ, Li Y, Gage FH, Mi S, Yao J (2018) CRISPR interference-based specific and efficient gene inactivation in the brain. Nat Neurosci 21(3):447-454. https:// doi.org/10.1038/s41593-018-0077-5

75. Larson MH, Gilbert LA, Wang X, Lim WA, Weissman JS, Qi LS (2013) CRISPR interference (CRISPRi) for sequence-specific control of gene expression. Nat Protoc 8(11):2180-2196. https://doi.org/10.1038/nprot.2013.132

76. Cong L, Zhou R, Kuo YC, Cunniff M, Zhang F (2012) Comprehensive interrogation of natural TALE DNA-binding modules and transcriptional repressor domains. Nat Commun 3(1):968. https://doi.org/10.1038/ncomms1962

77. Laufer BI, Singh SM (2015) Strategies for precision modulation of gene expression by epigenome editing: an overview. Epigenetics Chromatin 8(1): 34. https://doi.org/10.1186/s13072-015-0023-7

78. Cano-Rodriguez D, Rots MG (2016) Epigenetic editing: on the verge of reprogramming gene expression at will. Curr Genet Med Rep 4(4):170-179. https://doi.org/10.1007/s40142-016-0104-3

79. Snowden AW, Gregory PD, Case CC, Pabo CO (2002) Gene-specific targeting of $\mathrm{H} 3 \mathrm{~K} 9$ methylation is sufficient for initiating repression in vivo. Curr Biol 12(24):2159-2166. https://doi.org/10.1016/S0960-9822(02)01391-X

80. Mendenhall EM, Williamson KE, Reyon D, Zou JY, Ram O, Joung JK, Bernstein BE (2013) Locus-specific editing of histone modifications at 
endogenous enhancers. Nat Biotechnol 31(12):1133-1136. https://doi.org/1 $0.1038 / \mathrm{nbt} .2701$

81. Gregory DJ, Zhang Y, Kobzik L, Fedulov AV (2013) Specific transcriptional enhancement of inducible nitric oxide synthase by targeted promoter demethylation. Epigenetics 8(11):1205-1212. https://doi.org/10.4161/epi.262 67

82. Chen L, Tang L, Xiang H, Jin L, Li Q, Dong Y, Wang W, Zhang G (2014) Advances in genome editing technology and its promising application in evolutionary and ecological studies. 3(1). https://doi.org/10.1186/2047-21 $7 X-3-24$

83. Ou K, Yu M, Moss NG, Wang YJ, Wang AW, Nguyen SC, Jiang C, Feleke E, Kameswaran V, Joyce EF, Naji A, Glaser B, Avrahami D, Kaestner KH (2019) Targeted demethylation at the CDKN1C/p57 locus induces human $\beta$ cell replication. J Clin Invest 129(1):209-214. https://doi.org/10.1172/JCl99170

84. Choudhury SR, Cui Y, Lubecka K, Stefanska B, Irudayaraj J (2016) CRISPRdCas9 mediated TET1 targeting for selective DNA demethylation at BRCA1 promoter. Oncotarget 7(29):46545-46556. https://doi.org/10.18632/oncota rget.10234

85. Kholosy WM, Visscher M, Ogink K, Buttstedt H, Griffin K, Beier A, Gerlach JP, Molenaar JJ, Geijsen N, de Boer M, Chatsisvili A (2021) Simple, fast and efficient iTOP-mediated delivery of CRISPR/Cas9 RNP in difficult-to-transduce human cells including primary T cells. J Biotechnol 338:71-80. https://doi. org/10.1016/j.jbiotec.2021.07.006

\section{Publisher's Note}

Springer Nature remains neutral with regard to jurisdictional claims in published maps and institutional affiliations.

\section{Submit your manuscript to a SpringerOpen ${ }^{\circ}$ journal and benefit from:}

- Convenient online submission

- Rigorous peer review

- Open access: articles freely available online

- High visibility within the field

- Retaining the copyright to your article

Submit your next manuscript at $\boldsymbol{\nabla}$ springeropen.com 